\title{
Gallstones are Associated with Intima- Media Thickness of Common Carotid Arteries in Men
}

\section{Jung-Hwan Kim, Jung-Gum Ryoo*, Jeong-Won Lee, Ji-Hye Kim}

Department of Family Medicine, IS Hallym Hospital, Incheon, Korea

Background: The prevalence of gallstone disease is increasing in Korea. Gallstone disease and atherosclerosis share common risk factors. Ultrasonographic carotid intima-media thickness is an independent predictor of atherosclerosis. We measured the carotid intima-media thickness among men who had gallstones to establish the association between atherosclerosis and gallstones.

Methods: A total of 330 men who visited the health promotion center of the IS Hallym Hospital from January 2011 to July 2012 were recruited. Both abdomen and carotid ultrasonographies were performed. Demographic, anthropometric, and biochemical data were collected.

Results: The prevalence of gallstones was 6.6\%. The carotid intima-media thickness, age, and body mass index were higher in subjects with gallstones ( $\mathrm{P}<0.05$ for all). After Pearson correlation analysis, gallstone, age, body mass index, and fasting blood sugar were significantly associated with carotid intima-media thickness. A statistically positive association between gallstone and carotid intima-media thickness was demonstrated in a multivariate analysis adjusted for age, body mass index, and fasting blood sugar.

Conclusion: Carotid intima-media thickness is higher in male subjects with gallstones, indicating that they are at greater risk for atherosclerosis.

Keywords: Gallstones; Carotid Intima-Media Thickness; Atherosclerosis; Men

\section{INTRODUCTION}

Recently the incidence of gallstone disease in Korea has increased due to Western-style diet, obesity, and increasing age. Gallstones are mostly asymptomatic, hence it is often found

Received: August 31, 2012, Accepted: March 5, 2014

${ }^{*}$ Corresponding Author: Jung-Gum Ryoo

Tel: +82-32-540-9072, Fax: +82-32-545-1844

E-mail: glia2000@naver.com

Korean Journal of Family Medicine

Copyright (C) 2014 The Korean Academy of Family Medicine

(ㄷ) This is an open-access article distributed under the terms of the Creative Commons Attribution Non-Commercial License (http://creativecommons.org/licenses/by-nc/3.0) which permits unrestricted noncommercial use, distribution, and reproduction in any medium, provided the original work is properly cited. by chance during abdomen ultrasonography. The prevalence of gallstone disease is different according to race and gender. Prevalence in Koreans has been reported as 3.1\% in males and $3.4 \%$ in females. ${ }^{1)}$ On the other hand, the prevalence in American Caucasians was $8.6 \%$ and $16.6 \%$ in males and females, respectively, and in American Hispanics it was 8.9\%, 26.7\% in males and females, respectively. ${ }^{2)}$ Gallstones can be classified into cholesterol stones, pigment stones, and mixed stones according to their composition. Cholesterol stones account for $90 \%$ or more in Western countries, whereas in Korea the proportion of pigment stones have been high, but recently there has been an increase in cholesterol stones. Generally black pigment stones and brown pigment stones have been classified as pigment stones. However, Kim et al. ${ }^{3)}$ reported that from the results of chemical analysis of black pigment stones and brown pigment stones, $45 \%$ of black 
pigment stones and $81 \%$ of brown pigment stones are cholesterol stones. Therefore the effect of cholesterol on gallstone formation may be greater in Koreans.

The established risk factors which cause cholesterol stones are old age, female, obesity ${ }^{4-6)}$ as well as pregnancy, oral contraceptives, alcohol, smoking, and diabetes. ${ }^{7-9)}$ Amongst these risk factors, age, obesity, smoking, and diabetes are the risk factors for atherosclerosis, ${ }^{10-13)}$ hence the proposed relationship between gallstones and atherosclerosis. Wysowski et al. ${ }^{14)}$ reported that the medical history of biliary disease is correlated with that of myocardial infarction, and Bortnichak et al. ${ }^{15)}$ reported that the risk for coronary artery disease is high in patients who had cholecystectomy. Thus, there are many studies which reported the relationship between biliary disease and atherosclerosis, but the relationship is still unclear.

Carotid ultrasonography is often used to assess the degree of atherosclerosis. Carotid intima media thickness (IMT) measured by ultrasound is an indicator for the degree of atherosclerosis of systemic and coronary arteries, ${ }^{16,17)}$ and several studies have reported it as a significant independent indicator for coronary artery disease and cerebral arterial disease. Cho et al. ${ }^{18)}$ reported that the maximum value of carotid IMT in Koreans is $0.69 \pm$ $0.18 \mathrm{~mm}$ in males and $0.67 \pm 0.16 \mathrm{~mm}$ in females, and Mannami et al. ${ }^{19)}$ reported that the mean carotid IMT in the Japanese population is $0.92 \pm 0.13 \mathrm{~mm}$ in males and $0.89 \pm 0.11 \mathrm{~mm}$ in females. Likewise, there have been efforts to gather IMT data by race and gender, but there are not enough data for the Korean population. In this study, we classified adult men under regular medical examination into a group who had discovered gallstones by chance and a group who did not have gallstones, and investigated the relationship between gallstones and atherosclerosis by comparing common carotid IMT.

\section{METHODS}

\section{Study Subjects}

Between the period of January 2011 to July 2012, amongst those under regular medical examination at the IS Hallym Hospital in Incheon, 330 adult males were recruited who had both abdomen and carotid ultrasonographies. The subjects with history of cholecystectomy, cardio-cerebrovascular disease or common carotid artery surgery were excluded.

\section{Data Collection}

The subjects rested for about 10 minutes prior to blood pressure measurement, then the blood pressure was measured with EASY X 800 R/C (Jawon, Gyeongsan, Korea), the automatic blood pressure manometer. If the blood pressure measured by the automatic device was $140 / 90 \mathrm{~mm} \mathrm{Hg}$ or over, it was re-measured with a mercury sphygmomanometer by a trained nurse. Automatic height-weight measure DS-102 (Jenix, Seoul, Korea) was used to measure height and weight, and body mass index $\left(\mathrm{BMI}, \mathrm{kg} / \mathrm{m}^{2}\right)$ was calculated by dividing the weight by height squared.

A blood test was conducted after fasting for at least 8 hours, and TBA-C16000 (Toshiba, Tokyo, Japan) was used for hemanalysis. Uric acid, total protein, albumin, total bilirubin, direct bilirubin, alkaline phosphatase (ALP), aspartate transaminase (AST), alanine transaminase (ALT), gammaglutamyl transpeptidase (r-GTP), total cholesterol, triglyceride, high density lipoprotein cholesterol (HDL-C), low density lipoprotein cholesterol (LDL-C), fasting glucose, hemoglobin $\mathrm{AlC}(\mathrm{HbAlc})$, white blood cell (WBC), and C-reactive protein (CRP) were measured.

Histories of hypertension, diabetes, surgery, smoking, drinking, and exercise were checked by a questionnaire. Drinking history was evaluated through the question, "On average, how many days do you drink in 1 week? Write the number of glasses per day." Individual drink quantity was defined as "days of drinking in 1 week $\times$ number of glasses per day." Also exercise was investigated by asking, "the number of days exercised to the point of shortness of breath for 20 minutes or longer for 1 week, the number of days exercised more breathlessly than usual for 30 minutes or longer lately for 1 week, and the number of days walked for 30 minutes or longer lately for 1week." Metabolic equivalent of tasks (METs) of the 1st, 2 nd, and 3rd question were counted as 1.5, 6, and 4, respectively, then the number of days were multiplied and the sum was defined as an individual exercise quantity.

\section{Carotid and Abdomen Ultrasonographies}

Carotid and abdomen ultrasonographies were carried out by a radiologist per subject, and a total of 6 radiologists participated. 
For carotid ultrasonography, a 5 to $12 \mathrm{MHz}$ linear probe of high resolution ultrasound (Philips iU22 Ultrasound System; Philips Healthcare, Cleveland, OH, USA) was used to measure by B-mode method. Carotid IMT was defined as the distance from the boundary of lumen of vessel and tunica intima to the boundary of tunica-media and tunica externa. ${ }^{20)}$ It was measured at the proximal part of the far wall from the boundary that transits the common carotid artery to the carotid bulb. The value of the biggest IMT was obtained from both common carotid arteries. With the presence of atherosclerotic plaques, it was measured at proximal part without atherosclerotic plaques. The atherosclerotic plaque was assumed when carotid IMT was 1.5 $\mathrm{mm}$ or greater and there was local thickness in the vessel.

For abdomen ultrasonography, a 2 to $5 \mathrm{MHz}$ curved probe of high resolution ultrasound (Phillips iU22 Ultrasound System, Philips Healthcare) was used to detect gallstones. Gallstones were assumed if there were echo movements according to posture change with echogenic and posterior acoustic shadow. ${ }^{21)}$

\section{Statistical Analysis}

PASW SPSS ver. 18.0 (SPSS Inc., Chicago, IL, USA) was used throughout all the statistical analysis. On comparison between the gallstone group and non-gallstone group, two independent sample tests were used for continuous variables that met normality assumption, and the Mann-Whitney test was used for those that did not meet normality assumption. Also Fisher's exact test was used for nominal variables. Carotid IMT and several variables (gender, age, uric acid, total protein, albumin, total bilirubin, direct bilirubin, ALP, AST, ALT, r-GTP, total cholesterol, triglyceride, HDL-C, LDL-C, fasting glucose, HbAlc, WBC, CRP, BMI, systolic blood pressure, diastolic blood pressure, hypertension, diabetes, smoking history, alcohol history, and exercise quantity) were examined with Pearson correlation coefficient, and multiple regression analysis was conducted for variables which showed correlation. The statistical significance was defined as a P-value less than 0.05 .

\section{RESULTS}

\section{General Characteristics of Study Subjects}

Out of 330 male subjects, there were 22 subjects who had gallstones by abdomen ultrasonography, while 308 subjects did not. The prevalence of gallstones in the study subjects was $6.6 \%$ with the mean age of 50.3 years old, and the mean maximum value of carotid IMT was $0.86 \mathrm{~mm}$. The mean BMI was $24.2 \mathrm{~kg} /$ $\mathrm{m}^{2}$, and the mean systolic and diastolic blood pressure were 124.7 $\mathrm{mm} \mathrm{Hg}$ and $76.0 \mathrm{~mm} \mathrm{Hg}$, respectively.

\section{Comparison between the Gallstone Group and the Non-Gallstone Group}

The maximum value of common carotid IMT, age and BMI were higher in the gallstone group $(\mathrm{P}=0.002, \mathrm{P}=0.008, \mathrm{P}=0.04$, respectively). There was no significant difference between the 2 groups for other factors (Table 1).

\section{The Relationship between the Maximum Value of Common Carotid Intima Media Thickness and Other Factors}

Correlation analysis was conducted to select factors related to the maximum value of common carotid IMT. Age $(r=0.324, \mathrm{P}<$ $0.001)$, BMI $(r=0.115, \mathrm{P}=0.04)$, gallstone $(\mathrm{r}=0.172, \mathrm{P}=0.002)$ and fasting glucose $(\mathrm{r}=0.116, \mathrm{P}=0.04)$ showed significant correlations. Multiple regression analysis was conducted on those significant factors to find out factors independently related to the maximum value of carotid IMT. Age (standardized coefficients $=0.312, \mathrm{P}<0.001), \mathrm{BMI}$ (standardized coefficients $=0.127, \mathrm{P}=$ 0.02 ), and gallstone (standardized coefficients $=0.109, \mathrm{P}=0.04$ ) were the independent factors (Tables 2, 3).

\section{DISCUSSION}

The prevalence of gallstone disease in Korean males was found to be $3.1 \%$ in a report by Lee et al. ${ }^{1}$ in 1997 , but it was $6.6 \%$ in this study. This is higher than the known prevalence and there are three possible reasons. First, the prevalence reported by Lee et al. ${ }^{1)}$ was age-standardized prevalence, but in this study, the age and BMI were relatively high with a mean age of 50.3 years and a mean BMI of $24.2 \mathrm{~kg} / \mathrm{m}^{2}$. Second, the prevalence of gallstone disease in Koreans is increasing due to adoption of Western style diet and lifestyle. ${ }^{21)}$ In addition, selective bias may have been a factor, as the abdomen ultrasonography is optional for the medical examination. 
Table 1. Baseline characteristics of the subjects

\begin{tabular}{|c|c|c|c|c|}
\hline Variable & Gallstone $(\mathrm{n}=22)$ & Non-gallstone $(\mathrm{n}=308)$ & Total $(\mathrm{n}=330)$ & P-value* \\
\hline CCA max-IMT (mm) & $0.99 \pm 0.18$ & $0.85 \pm 0.21$ & $0.86 \pm 0.21$ & 0.002 \\
\hline Age (y) & $56.1 \pm 10.1$ & $49.9 \pm 8.3$ & $50.3 \pm 8.6$ & 0.008 \\
\hline Uric acid (mg/dL) & $6.0 \pm 1.6$ & $5.7 \pm 1.2$ & $5.7 \pm 1.3$ & 0.96 \\
\hline Total protein (g/dL) & $7.4 \pm 0.4$ & $7.3 \pm 0.4$ & $7.3 \pm 0.4$ & 0.70 \\
\hline Albumin (g/dL) & $4.3 \pm 0.2$ & $4.3 \pm 0.2$ & $4.3 \pm 0.2$ & 0.46 \\
\hline Total bilirubin (mg/dL) & $1.0 \pm 0.3$ & $1.1 \pm 0.4$ & $1.1 \pm 0.4$ & 0.40 \\
\hline Direct bilirubin (mg/dL) & $0.3 \pm 0.1$ & $0.3 \pm 0.1$ & $0.3 \pm 0.1$ & 0.61 \\
\hline $\operatorname{ALP}(\mathrm{IU} / \mathrm{L})$ & $172.0 \pm 44.3$ & $195.6 \pm 65.7$ & $194.0 \pm 64.7$ & 0.10 \\
\hline AST (IU/L) & $28.1 \pm 15.0$ & $28.2 \pm 19.9$ & $28.2 \pm 19.6$ & 0.84 \\
\hline ALT (IU/L) & $28.2 \pm 22.4$ & $29.4 \pm 25.3$ & $29.3 \pm 25.0$ & 0.87 \\
\hline r-GTP (IU/L) & $49.3 \pm 35.6$ & $54.0 \pm 89.6$ & $53.7 \pm 87.0$ & 0.90 \\
\hline Total cholesterol (mg/dL) & $191.3 \pm 36.6$ & $195.3 \pm 35.5$ & $195.0 \pm 35.6$ & 0.61 \\
\hline Triglyceride (mg/dL) & $190.4 \pm 224.7$ & $133.0 \pm 92.1$ & $136.8 \pm 106.5$ & 0.37 \\
\hline HDL-C (mg/dL) & $47.5 \pm 10.4$ & $48.4 \pm 11.2$ & $48.3 \pm 11.2$ & 0.73 \\
\hline LDL-C (mg/dL) & $119.3 \pm 33.1$ & $132.2 \pm 32.6$ & $131.3 \pm 32.8$ & 0.08 \\
\hline FBS (mg/dL) & $97.9 \pm 25.8$ & $94.2 \pm 19.9$ & $94.5 \pm 20.1$ & 0.91 \\
\hline HbAlc (\%) & $5.7 \pm 0.9$ & $5.4 \pm 0.7$ & $5.4 \pm 0.8$ & 0.15 \\
\hline $\mathrm{WBC}\left(\times 10^{3} / \mathrm{uL}\right)$ & $7.2 \pm 2.6$ & $6.4 \pm 1.8$ & $6.5 \pm 1.9$ & 0.26 \\
\hline $\mathrm{CRP}(\mathrm{mg} / \mathrm{dL})$ & $0.2 \pm 0.3$ & $0.2 \pm 0.3$ & $0.2 \pm 0.3$ & 0.14 \\
\hline $\operatorname{BMI}\left(\mathrm{kg} / \mathrm{m}^{2}\right)$ & $24.9 \pm 1.8$ & $24.1 \pm 2.7$ & $24.2 \pm 2.5$ & 0.04 \\
\hline SBP (mm Hg) & $125.6 \pm 15.5$ & $124.6 \pm 13.4$ & $124.7 \pm 13.5$ & 0.66 \\
\hline DBP (mm Hg) & $74.1 \pm 9.8$ & $76.2 \pm 9.3$ & $76.0 \pm 9.4$ & 0.31 \\
\hline HTN & & & & 0.22 \\
\hline Present & 3 & 24 & 27 & \\
\hline Absent & 10 & 176 & 186 & \\
\hline Unknown & 9 & 108 & 117 & \\
\hline $\mathrm{DM}$ & & & & 0.54 \\
\hline Present & 1 & 11 & 12 & \\
\hline Absent & 12 & 189 & 201 & \\
\hline Unknown & 9 & 108 & 117 & \\
\hline Smoking & & & & 0.55 \\
\hline Never & 3 & 70 & 73 & \\
\hline Current/ex-smoker & 10 & 129 & 139 & \\
\hline Unknown & 9 & 109 & 118 & \\
\hline Alcohol $^{\dagger}$ & $11.3 \pm 10.4(\mathrm{n}=13)$ & $15.5 \pm 19.2(\mathrm{n}=198)$ & $15.2 \pm 18.8(\mathrm{n}=211)$ & 0.44 \\
\hline Exercise $^{\ddagger}$ & $9.6 \pm 5.1(n=12)$ & $7.2 \pm 4.9(\mathrm{n}=184)$ & $7.4 \pm 4.9(\mathrm{n}=196)$ & 0.11 \\
\hline
\end{tabular}

Values are presented as mean \pm SD or number.

CCA-max IMT: maximal intima-media thickness of both common carotid arteries, ALP: alkaline phosphatase, AST: aspartate transaminase, ALT: alanine transaminase, r-GTP: gamma-glutamyl transpeptidase, HDL-C: high density lipoprotein cholesterol, LDL-C: low density lipoprotein cholesterol, FBS: fasting blood sugar, HbAlc: hemoglobin A1C, WBC: white blood cell, CRP: C-reactive protein, BMI: body mass index calculated as weight in kilograms divided by height in meters squared, SBP: systolic blood pressure, DBP: diastolic blood pressure, HTN: hypertension, DM: diabetes mellitus.

*From Student t-test for CCA max-IMT, total protein, albumin, total bilirubin, ALP, total cholesterol, HDL-C, LDL-C, BMI, SBP, DBP, alcohol, and exercise, Mann-Whitney test for age, uric acid, direct bilirubin, AST, ALT, r-GTP, triglyceride, FBS, HbAlc, WBC, and CRP, or Fisher's exact test for HTN, DM, and smoking. ${ }^{\dagger}$ Alcohol is presented as the result of the days per week one drinks multiplied by the number of cups one drinks a day. ${ }^{\ddagger}$ Exercise is presented as the sum of the first answer multiplied by 1.5 and the second answer multiplied by 6 and the third answer multiplied by 4 . 
Table 2. Variables associated with maximal intima-media thickness of both common carotid arteries

\begin{tabular}{lcc}
\hline \multicolumn{1}{c}{ Variable } & $\mathrm{r}$ & P-value* $^{*}$ \\
\hline Age $(\mathrm{y})$ & 0.324 & $<0.001$ \\
Body mass index $\left(\mathrm{kg} / \mathrm{m}^{2}\right)$ & 0.115 & 0.036 \\
Gallstone (yes) & 0.172 & 0.002 \\
Fasting blood sugar $(\mathrm{mg} / \mathrm{dL})$ & 0.116 & 0.035 \\
\hline
\end{tabular}

*From Pearson correlation analysis.

The established risk factors for gallstone disease in the previous studies were old age, obesity and female, ${ }^{4-6)}$ as well as pregnancy, oral contraceptives, alcohol, smoking, and diabetes. ${ }^{7-9)}$ In this study, age and BMI in the gallstone group was higher than the non-gallstone group (Table 1). The relationship between cholesterol level and gallstone disease has not been established, ${ }^{22)}$ and the two showed no association in this study. Also, there was a report about an increase in gallstone disease in type 2 diabetes, ${ }^{1)}$ but the correlation was not found in this study.

Increase in carotid IMT is known as an independent factor for coronary artery disease, and recently, correlation to cerebrovascular disease has been reported. A meta-analysis of Lorenz et al. ${ }^{23)}$ reported that an increase in carotid IMT by 0.10 $\mathrm{mm}$ increased the incidence of myocardial infarction by 1.15 (95\% confidence interval [CI], 1.12 to 1.17 ), and stroke by 1.18 (95\% CI, 1.16 to 1.21), when age and gender were adjusted. Age, systolic blood pressure, and BMI are known factors that increase carotid IMT, ${ }^{18,24,25)}$ but in this study, age, BMI, gallstone, and fasting glucose showed correlation with the maximum value of carotid IMT.

Recently Mendez-Sanchez et al. ${ }^{26)}$ reported that carotid IMT increased in gallstone patients and a $0.1 \mathrm{~mm}$ increase in carotid IMT increased the prevalence of gallstone disease by 1.25 times (95\% CI, 1.02 to 1.53; P = 0.027). Also Mendez-Sanchez et al. ${ }^{27}$ ) reported that patients with coronary artery disease were at higher risk for gallstone disease (odds ratio, 2.84), and Chavez-Tapia et $\mathrm{al}^{28)}$ reported that patients undergoing cholecystectomy were at greater risk for cardiovascular disease.

In Western countries cholesterol stones account for $90 \%$ or more, but in Korea they account for 50\%. Recently the incidence of cholesterol stones is increasing due to westernization, but this phenomenon occurs mainly in women with increases in obesity
Table 3. Relationships between maximal intima-media thickness of both common carotid arteries and some variables in a multivariate model

\begin{tabular}{lcc}
\hline \multicolumn{1}{c}{ Variable } & $\begin{array}{c}\text { Standardized } \\
\text { coefficient }\end{array}$ & P-value* \\
\hline Age $(\mathrm{y})$ & 0.312 & $<0.001$ \\
Body mass index $\left(\mathrm{kg} / \mathrm{m}^{2}\right)$ & 0.127 & 0.02 \\
Gallstone (yes) & 0.109 & 0.04 \\
Fasting blood sugar $(\mathrm{mg} / \mathrm{dL})$ & 0.070 & 0.18 \\
\hline
\end{tabular}

*From multiple regression analysis.

and age. Therefore, it was not clear whether the study by MendezSanchez et al. is applicable to the middle-aged Korean male population, but the maximum value of common carotid IMT also increased in Korean men who had gallstones.

This study is meaningful from the standpoint that it reported the relationship between gallstones and carotid IMT in the Korean male population by analyzing most risk factors for gallstone disease and atherosclerosis, but there were a few limitations. First, the sample size was relatively small and the subjects were limited to males, so it is impractical to generalize to the whole population including females. Second, some data about history of hypertension, diabetes, exercise, smoking, and alcohol intake were missing, so it was difficult to conduct an accurate evaluation about them. Third, ultrasonography was conducted solely by the radiologist, but 6 different radiologists were employed for ultrasonography, hence individual technical difference and possibility of error cannot be ruled out. Fourth, the subjects were selected amongst people under medical examination who had both abdomen and carotid ultrasonographies, and those tests were optional, hence there is a possibility of selective bias. As a result, those people who could financially afford both tests, were generally interested in health, or had risk factors for cardio-cerebrovascular disease would have been included in the study subjects. Fifth, 'the sum of days $x$ METs' was used to evaluate exercise quantity, but it was a selfdesigned evaluation method which had limitations in feasibility and standardization. Sixth, only the maximum value was used for the measurement of common carotid IMT, but if the evaluation included the mean values measured from both carotid arteries or several areas of a unilateral artery, more significant results could 
have been obtained.

In conclusion, the maximum value of common carotid IMT increased significantly with presence of gallstones and with increases in age, BMI, and fasting glucose. The presence of gallstones was independently significant to the maximum value of common carotid IMT, which means that gallstones are closely related to atherosclerosis in men.

\section{CONFLICT OF INTEREST}

No potential conflict of interest related with this article was reported.

\section{REFERENCES}

1. Lee JK, Rhee PL, Lee JH, Lee KT, Choi SH, Noh JH, et al. Prevalence and risk factors of gallstone in health screening people. Korean J Gastroenterol 1997;29:85-92.

2. Everhart JE, Khare M, Hill M, Maurer KR. Prevalence and ethnic differences in gallbladder disease in the United States. Gastroenterology 1999;117:632-9.

3. Kim JH, Kim HS, Lee JS, Lee MS, Cho SW, Lee MH, et al. Comparative study between the ultrasonic pattern and the chemical analysis of composition of the gallstone. Korean J Gastroenterol 1992;24:1119-29.

4. Barbara L, Sama C, Morselli Labate AM, Taroni F, Rusticali AG, Festi D, et al. A population study on the prevalence of gallstone disease: the Sirmione Study. Hepatology 1987;7: 913-7.

5. Attili AF, Carulli N, Roda E, Barbara B, Capocaccia L, Menotti A, et al. Epidemiology of gallstone disease in Italy: prevalence data of the Multicenter Italian Study on Cholelithiasis (M.I.COL.) Am J Epidemiol 1995;141:15865.

6. Pacchioni M, Nicoletti C, Caminiti M, Calori G, Curci V, Camisasca R, et al. Association of obesity and type II diabetes mellitus as a risk factor for gallstones. Dig Dis Sci 2000;45: 2002-6.

7. Valdivieso V, Covarrubias C, Siegel F, Cruz F. Pregnancy and cholelithiasis: pathogenesis and natural course of gallstones diagnosed in early puerperium. Hepatology 1993;17:1-4.

8. Petitti DB, Friedman GD, Klatsky AL. Association of a history of gallbladder disease with a reduced concentration of highdensity-lipoprotein cholesterol. N Engl J Med 1981;304: 1396-8.

9. De Santis A, Attili AF, Ginanni Corradini S, Scafato E, Cantagalli A, De Luca C, et al. Gallstones and diabetes: a casecontrol study in a free-living population sample. Hepatology 1997;25:787-90.

10. Harris T, Cook EF, Kannel WB, Goldman L. Proportional hazards analysis of risk factors for coronary heart disease in individuals aged 65 or older: The Framingham Heart Study. J Am Geriatr Soc 1988;36:1023-8.

11. Wilson PW, Bozeman SR, Burton TM, Hoaglin DC, BenJoseph R, Pashos CL. Prediction of first events of coronary heart disease and stroke with consideration of adiposity. Circulation 2008;118:124-30.

12. Njolstad I, Arnesen E, Lund-Larsen PG. Smoking, serum lipids, blood pressure, and sex differences in myocardial infarction: a 12-year follow-up of the Finnmark Study. Circulation 1996;93:450-6.

13. Kannel WB, McGee DL. Diabetes and cardiovascular risk factors: the Framingham study. Circulation 1979;59:8-13.

14. Wysowski DK, Goldberg EL, Comstock GW, Diamond EL. A study of a possible association between breast cancer and gallbladder disease. Am J Epidemiol 1986;123:532-43.

15. Bortnichak EA, Freeman DH Jr, Ostfeld AM, Castelli WP, Kannel WB, Feinleib M, et al. The association between cholesterol cholelithiasis and coronary heart disease in Framingham, Massachusetts. Am J Epidemiol 1985;121:1930.

16. O’Leary DH, PolakJF, Kronmal RA, Manolio TA, Burke GL, Wolfson SK Jr. Carotid-artery intima and media thickness as a risk factor for myocardial infarction and stroke in older adults. Cardiovascular Health Study Collaborative Research Group. N Engl J Med 1999;340:14-22.

17. Grobbee DE, Bots ML. Carotid artery intima-media thickness as an indicator of generalized atherosclerosis. J Intern Med 1994;236:567-73.

18. Cho YL, Kim DJ, Kim HD, Choi SH, Kim SK, Kim HJ, et al. Reference values of carotid artery intima-media thickness and association with atherosclerotic risk factors in healthy subjects 
in Korea. Korean J Med 2003;64:275-83.

19. Mannami T, Konishi M, Baba S, Nishi N, Terao A. Prevalence of asymptomatic carotid atherosclerotic lesions detected by high-resolution ultrasonography and its relation to cardiovascular risk factors in the general population of a Japanese city: the Suita study. Stroke 1997;28:518-25.

20. Bang DW, Shim YS, Park BW, Hyon MS, Kim SK, Kwon YJ. Carotid ultrasonography in patients with coronary artery disease. Korean J Med 2007;73:11-7.

21. Chung YJ, Park YD, Lee HC, Cho HJ, Park KS, Seo EH, et al. Prevalence and risk factors of gallstones in a general health screened population. Korean J Med 2007;72:480-90.

22. Marks JW, Cleary PA, Albers JJ. Lack of correlation between serum lipoproteins and biliary cholesterol saturation in patients with gallstones. Dig Dis Sci 1984;29:1118-22.

23. Lorenz MW, Markus HS, Bots ML, Rosvall M, Sitzer M. Prediction of clinical cardiovascular events with carotid intima-media thickness: a systematic review and metaanalysis. Circulation 2007; 115:459-67.

24. Veller MG, Fisher CM, Nicolaides AN, Renton S, Geroulakos
G, Stafford NJ, et al. Measurement of the ultrasonic intimamedia complex thickness in normal subjects. J Vasc Surg 1993; 17:719-25.

25. Kawamori R, Yamasaki Y, Matsushima H, Nishizawa H, Nao $\mathrm{K}$, Hougaku H, et al. Prevalence of carotid atherosclerosis in diabetic patients: ultrasound high-resolution B-mode imaging on carotid arteries. Diabetes Care 1992;15:1290-4.

26. Mendez-Sanchez N, Zamora-Valdes D, Flores-Rangel JA, Perez-Sosa JA, Vasquez-Fernandez F, Lezama-Mora JI, et al. Gallstones are associated with carotid atherosclerosis. Liver Int 2008;28:402-6.

27. Mendez-Sanchez N, Bahena-Aponte J, Chavez-Tapia NC, Motola-Kuba D, Sanchez-Lara K, Ponciano-Radriguez G, et al. Strong association between gallstones and cardiovascular disease. Am J Gastroenterol 2005;100:827-30.

28. Chavez-Tapia NC, Kinney-Novelo IM, Sifuentes-Renteria SE, Torres-Zavala M, Castro-Gastelum G, Sanchez-Lara K, et al. Association between cholecystectomy for gallstone disease and risk factors for cardiovascular disease. Ann Hepatol 2012; $11: 85-9$ 